Journal of Research in Interprofessional

Practice and

Education

Vol. 5.1

May 2015

\title{
Community Service Learning: An Effective Vehicle for Interprofessional Education
}

\author{
Taline D. Infante ${ }^{1}, \mathrm{RDH}, \mathrm{S}$, EdD; Lyda C. Arevalo-Flechas, PhD, RN; \\ Lark A. Ford, RN; M. Norma Partida, MS, DDS; Norma S. Ketchum, MS; \\ Brad H. Pollock, MPH, PhD; \& Anthony J. Infante, MD, PhD
}

\begin{abstract}
Background: Health professions students have limited exposure to each other during education and training, yet there are many expectations for interaction in the workplace as part of functioning healthcare teams. We reasoned that providing students an opportunity to work together in a service-learning project under faculty supervision would enhance student knowledge and appreciation of each other's disciplines and give them a better understanding of working together.

Methods and Findings: Teams of students from four disciplines (medicine, nursing, dentistry, dental hygiene) worked as volunteers with a unique population of transitional homeless families to develop individualized health and wellness plans. Preand post-participation surveys were used to measure changes in student perceptions of working in multidisciplinary teams, and focus groups were used to identify strengths and weaknesses of the project and future directions.

Conclusions: Results showed positive predispositions to working with each other, which were further enhanced by collaborative, interprofessional experience. Students' confidence in working together in multidisciplinary teams and understanding of the training and expertise of other professions increased after participation, and changes were statistically significant. Interprofessional education and community service-based learning may be a powerful combination for demonstrating the value of clinical teamwork to health professions students.
\end{abstract}

Keywords: Community service learning; Interprofessional education

\section{Introduction}

Journal of Research in Interprofessional Practice and Education (JRIPE)

Vol. 5.1

(C) 2015

Corresponding author: Anthony J. Infante. Email: infantea@uthscsa.edu
Increasingly, healthcare providers work in multidisciplinary teams to optimize individual patient and community health. Collaboration and teamwork among healthcare providers who will be working in clinical settings may be enhanced by clinical education and training that emphasizes mutual understanding and appreciation of the background, education, training, professional standards, and skills of the team members. Physicians and nurses work together on a daily basis; however, their education is separate and opportunities to interact during medical and nursing school are minimal. Only about $15 \%$ of medical and nursing schools have interdisciplinary 
2

Service Learning for Interprofessional Education

Infante, ArevaloFlechas, Ford, Partida, Ketchum, Pollock, \& Infante

Journal of Research in Interprofessional Practice and Education

Vol. 5.1

May 2015 programs [1,2]. Similarly, dentists and dental hygienists work together in clinical practice upon graduation, but, according to the Commission on Dental Accreditation, only $5 \%$ of US dental hygiene programs are even located in the same institution as dental programs [G. Welling, personal communication, Sept. 2, 2009]. Moreover, dental hygiene programs housed in the same institution have minimal collaborative educational opportunities for the dental and dental hygiene student. Finally, the majority of US medical and dental programs are located in the same institution, yet medical and dental students rarely take classes or participate in clinical rotations together. A potential result of this separation is stereotyping and the development of negative attitudes [3], which may have a direct impact on subsequent patient care [4].

Interprofessional education (IPE) is a mechanism to facilitate teamwork and relationships among healthcare professionals in different disciplines by encouraging favourable attitudes and behaviours. The Centre for the Advancement of Interprofessional Education provides a commonly cited definition of IPE: "Interprofessional education occurs when two or more professions learn with, from and about each other to improve collaboration and the quality of care" [5]. The World Health Organization (WHO) released a report in 1988 describing the growing body of evidence that shows how IPE has a positive impact on the provision of health care [6]. According to the WHO, teamwork has a greater impact on healthcare outcomes compared to individual team members working separately. The theoretical framework of IPE continues to evolve. Clark emphasizes collaborative and experiential learning as a social process fundamental to IPE [7]. In his view, students learn more from each other than they do from the instructor. They come to recognize that "the teamwork process is the learning experience."

The concept of the RESPECT (Realizing Enhanced Student inter-Professional Education through Clinical Teamwork) project was to create an interdisciplinary clinical training opportunity for dental, dental hygiene, medical, and nursing students to work together in teams to evaluate the health and wellness of an underserved population. RESPECT was designed to put the learning process in the context of the healthcare team by taking advantage of students' desire to engage in community service-based learning (CSL), defined as "a teaching and learning strategy that integrates meaningful community service with instruction and reflection to enrich the learning experience, teach civic responsibility, and strengthen communities" [8]. Team-building exercises and collaborative and experiential learning were emphasized over didactic, instructor-driven education. Student participants completed a questionnaire before and after the IPE experience to assess changes in attitudes and perceptions about working in healthcare teams and also shared perceptions about interprofessional collaboration in a focus group discussion. The results of the surveys showed statistically significant increases in student knowledge of other health professions and confidence in working together.

\section{Methods}

The SAMMinistries (http://www.samm.org/) Transitional Living and Learning Center (TLLC) residence provides free housing for up to two years for homeless fam- 
3

Service Learning for Interprofessional Education

Infante, ArevaloFlechas, Ford, Partida, Ketchum, Pollock, \& Infante

Journal of Research in Interprofessional Practice and Education

Vol. 5.1

May 2015 ilies with children, as long as the adults are sober, drug-free, and seeking employment or enrolled in an educational program. The University of Texas Health Science Center at San Antonio (UTHSCSA) Student-Run Free Clinics (http://studentrunclinics.org/) utilize the TLLC to provide an informal, non-threatening, collegial environment for introducing students to the benefits of CSL and addressing the healthcare needs of the residents, many of whom are uninsured. We reasoned that this environment would be ideal for the purpose of creating multidisciplinary health professions student teams and studying IPE in the setting of CSL.

Medical, nursing, dental, and dental hygiene students and respective faculty were recruited from existing selective courses and programs involving humanism, humanities, community service, and CSL. Investigation of the influence of an IPE experience on students' knowledge and attitudes was deemed to be exempted educational research by the UTHSCSA Institutional Review Board.

Students participated in five RESPECT sessions lasting four hours each on Saturday mornings. Students initially met in a team-building session facilitated by an experienced outside consultant that explored group decision-making, conflict mediation, alliance building, and cultural identity. Students discussed differences in background, education, training, and standards of the nursing, medical, dental hygiene, and dental professions. In session two, four interdisciplinary teams were formed consisting of a dental, dental hygiene, medical, and nursing student in each team $(N=$ 16 students) and assigned to selected multi-individual families at the TLLC. In sessions three and four, students, with the help of faculty, conducted oral and medical health interviews and physical examinations, including oral health exams, on family members. Based on the results of these interactions, student teams developed health and wellness plans for the families and in session five presented verbal and written recommendations for tailored healthcare interventions to the families. Session five concluded with a debriefing and discussion.

In the absence of generally accepted tools for measuring the impact of IPE [9], the investigators designed a specific survey relevant to the project. The survey consisted of 29 questions, each with a five-point Likert scale, to measure the following domains: students' participation concerns (five questions), attitudes toward IPE (five questions), confidence in working as members of healthcare teams (six questions), and understanding of the training involved in the four disciplines and of homeless populations (five questions). Five questions requested student self-assessment of their participation and performance. Three questions addressed issues of working with homeless populations. The specific questions and corresponding Likert scales are indicated in Tables 1-5. The questionnaire was administered prior to the RESPECT experience (pre-activity) and at the end of the experience (post-activity). A total of 50 students were surveyed; additional students were recruited in year two and three to account for dropouts. A total of 48 students completed both pre- and post-activity surveys. The five-point Likert scale responses were converted to numeric results on a scale of 1 to 5 . Mean and median score for pre- and post-activity survey responses with standard deviation and inter-quartile range were computed for each item. Matched student survey responses before and after the activity were assessed 
JRIPE

4

Service Learning for Interprofessional Education

Infante, ArevaloFlechas, Ford, Partida, Ketchum, Pollock, \& Infante

Journal of Research in Interprofessional Practice and Education

Vol. 5.1

May 2015 for significant change using a Wilcoxon signed-rank test due to the ordinal nature of the Likert scale data. Statistical tests were performed at the significance level of .05 (2-sided) and all statistical analyses were conducted using SAS (version 9.3, SAS Institute Inc., Cary, NC). A post-participation focus group interview was conducted by faculty members to uncover prevalent attitudes, behaviours, and perceptions that students derived from participation.

\section{Results}

Student surveys were conducted over three years of the project. In year one, 15 of 16 students completed both pre- and post-activity surveys. In year two, 16 of 16 students completed both surveys, and in year three, 17 of 18 students completed both surveys. We combined the three years' worth of data because preliminary analysis indicated that survey results did not differ according to year. Students were recruited in equal numbers from each of the four disciplines (medical, nursing, dental, and dental hygiene). The result yielded a total of 48 paired responses to be analyzed for most items. For items dealing with understanding of different disciplines, students did not rate change in understanding of their own discipline, yielding 36 paired responses (Table 4). Questions related to working with homeless families at the SAMM-TLLC were not part of the pre-activity survey in the first year (Tables 4 and 5). Results of the pre- and post-activity surveys are shown in Tables 1-5, and the key findings are summarized below for students concerns, attitudes, and confidence related to IPE, understanding of other health professions, and self-assessment of IPE capacity.

Table 1

\section{Concerns about an interprofessional education (IPE) patient care experience}

\begin{tabular}{|c|c|c|c|c|}
\hline & \multicolumn{2}{|c|}{$N$} & \multicolumn{2}{|c|}{$\begin{array}{l}\text { Median }[\mathrm{IQR}] \\
\text { Mean (SD) }\end{array}$} \\
\hline I am concerned that: & Pre & Post & Pre & Post \\
\hline $\begin{array}{l}\text { I will be (was) nervous working in a new clinical situation with } \\
\text { students from other programs. }{ }^{1}\end{array}$ & 48 & 50 & $\begin{array}{l}4.0[3.0,4.0] \\
3.56(0.97)\end{array}$ & $\begin{array}{l}4.0[4.0,5.0] \\
4.12(0.87)\end{array}$ \\
\hline I will slow down (slowed down) or hinder(ed) the patients care. ${ }^{1}$ & 48 & 50 & $\begin{array}{c}4.0[4.0,4.0] \\
3.94(0.63)\end{array}$ & $\begin{array}{l}4.0[4.0,5.0] \\
4.38(0.67)\end{array}$ \\
\hline $\begin{array}{l}\text { Students from different schools will not be able (were not able) to } \\
\text { work together because we have different skills and knowledge. }{ }^{1}\end{array}$ & 48 & 50 & $\begin{array}{l}4.0[4.0,5.0] \\
4.23(0.72)\end{array}$ & $\begin{array}{l}5.0[4.0,5.0] \\
4.60(0.49)\end{array}$ \\
\hline $\begin{array}{l}\text { I will (did) not learn anything valuable from IPE that will help me } \\
\text { in my own educational program. }{ }^{1}\end{array}$ & 48 & 50 & $\begin{array}{l}4.5[4.0,5.0] \\
4.48(0.55)\end{array}$ & $\begin{array}{l}5.0[4.0,5.0] \\
4.68(0.47)\end{array}$ \\
\hline $\begin{array}{l}\text { I will not be able to (did not) make a useful contribution to my } \\
\text { team. }{ }^{1}\end{array}$ & 48 & 50 & $\begin{array}{c}4.0[4.0,5.0] \\
4.21(0.74)\end{array}$ & $\begin{array}{l}5.0[4.0,5.0] \\
4.66(0.52)\end{array}$ \\
\hline
\end{tabular}

Notes: IQR = inter-quartile range; SD = standard deviation; 5-point Likert scale: strongly agree (1), agree (2), uncertain (3), disagree (4) and strongly disagree (5); ${ }^{1}$ Wilcoxon signed rank test $p<.05$ 


\section{JRIPE}

5

Service Learning for Interprofessional Education

Infante, ArevaloFlechas, Ford, Partida, Ketchum, Pollock, \& Infante

\section{Concerns}

Overall, students had few serious concerns about their participation in IPE, either from a practical or an academic standpoint (Table 1). Because of the way the concerns were presented, a response of "disagree" demonstrated minimal concerns. Overall, there was minimal change in level of concern about IPE from pre- to post-activity.

\section{Attitudes}

Students overwhelmingly agreed or strongly agreed from the outset that understanding the roles of other team members was important and that participation in interdisciplinary teams should be a part of their clinical training. Likewise, students agreed that the team activity was good preparation for clinical practice and helped with conflict resolution and collective decision-making. This group of students already held these pro-IPE perspectives before participating in the RESPECT experience, and continued to hold these positive views on the post-activity survey (Table 2).

\section{Table 2}

\section{Attitudes about interprofessional education (IPE)}

\begin{tabular}{|l|c|c|c|c|}
\hline & \multicolumn{2}{|c|}{$N$} & \multicolumn{2}{c|}{$\begin{array}{l}\text { Median [IQR] } \\
\text { Mean (SD) }\end{array}$} \\
\hline Item & Pre & Post & Pre & \multicolumn{1}{|c|}{ Post } \\
\hline $\begin{array}{l}\text { Students in different health professions schools should have edu- } \\
\text { cational and clinical experiences together to prepare for patient } \\
\text { care after we graduate. }\end{array}$ & 48 & 50 & $\begin{array}{l}1.0[1.0,2.0] \\
1.44(0.50)\end{array}$ & $\begin{array}{l}1.0[1.0,2.0] \\
1.26(0.44)\end{array}$ \\
\hline $\begin{array}{l}\text { It is important for health professions education students to under- } \\
\text { stand each other's skills and roles in patient care. }\end{array}$ & 48 & 50 & $\begin{array}{l}1.0[1.0,1.5] \\
1.25(0.44)\end{array}$ & $\begin{array}{l}1.0[1.0,1.0] \\
1.18(0.39)\end{array}$ \\
\hline $\begin{array}{l}\text { Working with students from another school will get (got) in the } \\
\text { way of my own learning. }\end{array}$ & 48 & 50 & $\begin{array}{l}4.0[4.0,5.0] \\
4.00(1.05)\end{array}$ & $\begin{array}{l}5.0[4.0,5.00 \\
4.50\end{array}$ \\
\hline $\begin{array}{l}\text { Interprofessional education will better prepare me (better pre- } \\
\text { pared me) for practice upon graduation. }\end{array}$ & 48 & 50 & $\begin{array}{l}2.0[1.0,2.0] \\
1.58(0.54)\end{array}$ & $\begin{array}{l}1.0[1.0,2.0] \\
1.30(0.46)\end{array}$ \\
\hline $\begin{array}{l}\text { Interprofessional education will help (helped) participating stu- } \\
\text { dents learn how to contribute to collective decision-making and } \\
\text { how to resolve conflicts. }{ }^{1}\end{array}$ & 48 & 50 & $\begin{array}{l}2.0[1.0,2.0] \\
1.56(0.50)\end{array}$ & $\begin{array}{l}1.0[1.0,2.0] \\
1.34(0.48)\end{array}$ \\
\hline
\end{tabular}

Notes: IQR = inter-quartile range; SD = standard deviation; 5-point Likert scale: strongly agree (1), agree (2), uncertain (3), disagree (4) and strongly disagree $(5) ;{ }^{1}$ Wilcoxon signed rank test $p<.05$

\section{Confidence}

Journal of Research in Interprofessional Practice and Education

Vol. 5.1

May 2015
Six items dealt with student confidence in accomplishing the group tasks of the project in the care of the homeless families (Table 3). Participation in RESPECT had a highly significant effect on student confidence. For all six of the IPE confidence items, there was a statistically significant enhancement in students' perception of confidence between the pre- and post-activity responses $(p<.05)$. 


\section{JRIPE}

6

Service Learning for Interprofessional Education

Infante, ArevaloFlechas, Ford, Partida, Ketchum, Pollock, \& Infante
Journal of Research in Interprofessional Practice and Education

Vol. 5.1

May 2015
Table 3

\section{Confidence in accomplishing tasks associated with an interprofessional approach to patient care}

\begin{tabular}{|l|c|l|l|l|}
\hline & \multicolumn{2}{|c|}{$N$} & \multicolumn{2}{c|}{$\begin{array}{c}\text { Median [IQR] } \\
\text { Mean (SD) }\end{array}$} \\
\hline How confident are you of each of the following? & Pre & Post & \multicolumn{1}{|c|}{ Pre } & \multicolumn{1}{|c|}{ Post } \\
\hline $\begin{array}{l}\text { Efficiently complete patient assessment \& treatment planning } \\
\text { when working in conjunction with students from other schools/ } \\
\text { other health professions. }\end{array}$ & 48 & 50 & $\begin{array}{l}2.0[2.0,3.0] \\
2.31(0.59)\end{array}$ & $\begin{array}{l}2.0[1.0,2.0] \\
1.68(0.62)\end{array}$ \\
\hline $\begin{array}{l}\text { Know responsibilities and capabilities of my student teammates } \\
\text { during patient appointments. }\end{array}$ & 48 & 50 & $\begin{array}{l}3.0[2.0,3.0] \\
2.63(0.67)\end{array}$ & $\begin{array}{l}2.0[1.0,2.0] \\
1.66(0.59)\end{array}$ \\
\hline $\begin{array}{l}\text { Assess findings from patient exams and jointly create a treatment } \\
\text { plan with my teammates. }\end{array}$ & 48 & 50 & $\begin{array}{l}2.0[2.0,3.0] \\
2.25(0.64)\end{array}$ & $\begin{array}{l}2.0[1.0,2.0] \\
1.58(0.54)\end{array}$ \\
\hline $\begin{array}{l}\text { Coordinate my activities with teammates from other schools so } \\
\text { there is not a lot of unproductive time. }{ }^{1}\end{array}$ & 48 & 50 & $\begin{array}{l}2.0[2.0,3.0] \\
2.35(0.67)\end{array}$ & $\begin{array}{l}2.0[1.0,2.0] \\
1.68(0.59)\end{array}$ \\
\hline $\begin{array}{l}\text { Understand what students from other schools/disciplines are say- } \\
\text { ing when we communicate about patients. }\end{array}$ & 48 & 50 & $\begin{array}{l}2.00[2.0,3.0] \\
2.27(0.54)\end{array}$ & $\begin{array}{l}2.0[1.0,2.0] \\
1.86(0.67)\end{array}$ \\
\hline $\begin{array}{l}\text { Complete patient records in a way they can be understood by all } \\
\text { members of my student team. }{ }^{1}\end{array}$ & 47 & 50 & $\begin{array}{l}2.0[2.0,3.0] \\
2.34(0.67)\end{array}$ & $\begin{array}{l}2.0[1.0,2.0] \\
1.80(0.64)\end{array}$ \\
\hline
\end{tabular}

Notes: IQR = inter-quartile range; SD = standard deviation; 5-point Likert scale: very confident (1), confident (2), moderate (3), not confident (4) and not at all confident $(5) ;{ }^{1}$ Wilcoxon signed rank test $p<.05$

Table 4

\section{Understanding of training}

\begin{tabular}{|l|l|l|l|l|}
\hline \multirow{2}{*}{$\begin{array}{l}\text { How would you rate your understanding of the training involved } \\
\text { in becoming each of these health professionals? }\end{array}$} & \multicolumn{2}{|c|}{$N$} & \multicolumn{3}{c|}{$\begin{array}{c}\text { Median [IQR] } \\
\text { Mean (SD) }\end{array}$} \\
\cline { 2 - 6 } & Pre & Post & \multicolumn{1}{|c|}{ Pre } & \multicolumn{1}{c|}{ Post } \\
\hline Dental hygienists $^{1}$ & 36 & 38 & $\begin{array}{l}3.0[2.0,3.0] \\
2.67(0.99)\end{array}$ & $\begin{array}{l}4.0[3.0,4.0] \\
3.87(0.74)\end{array}$ \\
\hline Dentists $^{1}$ & 36 & 38 & $\begin{array}{l}3.0[3.0,4.0] \\
3.22(0.87)\end{array}$ & $\begin{array}{l}4.0[3.0,4.0] \\
3.87(0.66)\end{array}$ \\
\hline Nurses $^{1}$ & 36 & 37 & $\begin{array}{l}3.0[2.0,3.0] \\
2.75(0.87)\end{array}$ & $\begin{array}{l}4.0[3.0,4.0] \\
3.84(0.76)\end{array}$ \\
\hline Physicians $^{1}$ & 36 & 37 & $\begin{array}{l}3.0[2.5,3.0] \\
3.00(0.96)\end{array}$ & $\begin{array}{l}4.0[3.0,5.0] \\
3.92(0.83)\end{array}$ \\
\hline How would you rate your knowledge level in working with home- $^{\text {less populations? }}{ }^{1}$ & 32 & 49 & $\begin{array}{l}3.0[2.0,3.0] \\
2.69(0.90)\end{array}$ & $\begin{array}{l}4.0[3.0,4.0] \\
3.69(0.68)\end{array}$ \\
\hline
\end{tabular}

Notes: IQR = inter-quartile range; $S D=$ standard deviation; 5-point Likert scale: very confident (1), confident (2), moderate (3), not confident (4) and not at all confident (5); ${ }^{1}$ Wilcoxon signed rank test $p<.05$ 


\section{JRIPE}

7

Service Learning for Interprofessional Education

Infante, ArevaloFlechas, Ford, Partida, Ketchum, Pollock, \& Infante

\section{Understanding of other health professions education} and the homeless

Students demonstrated significant changes $(p<.05)$ in understanding of the training experienced by the other healthcare disciplines represented in the project (Table 4). Likewise, students also expressed increased understanding of issues pertaining to working with homeless populations, which was statistically significant.

\section{Self-assessment}

For the self-assessment items, students reported enhanced appraisals of their individual contributions to group dynamics, including goal and priority setting, decisionmaking, delegation of responsibilities, respect for the opinions of others, and ability to resolve conflicts. While their pre-activity self-assessment was generally favourable in these areas, there were significant positive changes in many of the self-assessment items (Table 5).

Table 5

\section{Self-assessment}

\begin{tabular}{|c|c|c|c|c|}
\hline \multirow{2}{*}{ How much confidence do you have in YOUR own ability to: } & \multicolumn{2}{|c|}{ N } & \multicolumn{2}{|c|}{$\begin{array}{l}\text { Median [IQR] } \\
\text { Mean (SD) }\end{array}$} \\
\hline & Pre & Post & Pre & Post \\
\hline Contribute to goal and priority setting by the group. ${ }^{1}$ & 48 & 50 & $\begin{array}{l}4.0[3.5,4.0] \\
3.85(0.65)\end{array}$ & $\begin{array}{l}4.0[4.0,5.0] \\
4.30(0.54)\end{array}$ \\
\hline Be part of collective decision-making. ${ }^{1}$ & 48 & 50 & $\begin{array}{l}4.0[4.0,4.0] \\
3.92(0.65)\end{array}$ & $\begin{array}{l}4.0[4.0,5.0] \\
4.44(0.50)\end{array}$ \\
\hline $\begin{array}{l}\text { Implement group decisions even if you do not completely agree } \\
\text { with these decisions. }{ }^{1}\end{array}$ & 48 & 50 & $\begin{array}{l}4.0[3.0,4.0] \\
3.63(0.67)\end{array}$ & $\begin{array}{l}4.0[4.0,5.0] \\
4.18(0.66)\end{array}$ \\
\hline Delegate tasks \& responsibilities to other team members. ${ }^{1}$ & 48 & 50 & $\begin{array}{l}4.0[3.0,4.0] \\
3.67(0.69)\end{array}$ & $\begin{array}{l}4.0[4.0,5.0] \\
4.22(0.62)\end{array}$ \\
\hline $\begin{array}{l}\text { Respect the opinions of group members even if you do not agree } \\
\text { with their positions. }{ }^{1}\end{array}$ & 48 & 50 & $\begin{array}{l}4.0[4.0,4.5] \\
4.13(0.61)\end{array}$ & $\begin{array}{l}4.0[4.0,5.0] \\
4.40(0.61)\end{array}$ \\
\hline Resolve conflicts within groups. ${ }^{1}$ & 48 & 50 & $\begin{array}{l}4.0[3.0,4.0] \\
3.81(0.67)\end{array}$ & $\begin{array}{l}4.0[4.0,5.0] \\
4.32(0.62)\end{array}$ \\
\hline $\begin{array}{l}\text { Develop rapport and trust when working with the SAMM TLLC } \\
\text { family. }\end{array}$ & 33 & 50 & $\begin{array}{l}4.0[4.0,5.0] \\
4.18(0.64)\end{array}$ & $\begin{array}{l}4.0[4.0,5.0] \\
4.38(0.60)\end{array}$ \\
\hline Formulate a realistic plan of care for the SAMM TLLC family. ${ }^{1}$ & 33 & 50 & $\begin{array}{l}4.0[3.0,4.0] \\
3.85(0.71)\end{array}$ & $\begin{array}{l}4.0[4.0,5.0] \\
4.30(0.54)\end{array}$ \\
\hline
\end{tabular}

Notes: IQR = inter-quartile range; $S D=$ standard deviation; 5-point Likert scale: very confident (1), confident (2), moderate (3), not confident (4) and not at all confident (5); ${ }^{1}$ Wilcoxon signed rank test $p<.05$ 
8

Service Learning for Interprofessional Education

Infante, ArevaloFlechas, Ford, Partida, Ketchum, Pollock, \& Infante

Journal of Research in Interprofessional Practice and Education

Vol. 5.1

May 2015

\section{Responses by discipline}

We analyzed the responses of the students grouped according to individual discipline (medicine, dentistry, nursing, dental hygiene), by medical (medicine, nursing) vs. oral health (dentistry, dental hygiene) orientation, and by doctoral (medicine, dentistry) vs. non-doctoral (nursing, dental hygiene) academic program. In virtually all cases, there were no significant differences by discipline; that is, a similar direction and degree of change pre- vs. post-activity occurred in all student groups. For example, in the med$\mathrm{ical} /$ nursing vs. dental/dental hygiene analysis, only 2 of 29 comparisons showed a statistically significant difference $(p<.05)$ among the groups. In both instances, dental students reported somewhat less positive change than the three other disciplines. Similarly, in the doctoral vs. non-doctoral program comparison, only 2 of 29 comparisons showed differences. The non-doctoral group (nursing and dental hygiene) reported greater positive change in these two cases. Finally, there were no significant differences between the changes in responses pre- vs. post-activity in the medical vs. oral health comparison.

\section{Focus group results}

During the final project session, students were asked to provide open-ended feedback on any aspect of the project. The following responses were notable.

The facilitator designed several "get to know each other" exercises for students and faculty. Students reported that outside facilitation and these team-building exercises were very helpful in getting the project off to a good start. After the team-building exercises, students were able to verbalize that "we could be friends" outside of the classroom with students from other disciplines.

Students had largely accurate observations about the different roles, boundaries, and overlaps between different disciplines. As expected, medical-nursing and dentalhygiene student dyads were most familiar with each other prior to RESPECT, but students from all four disciplines appreciated the interactions and described increased understanding of the training and roles of each discipline.

Students observed that the SAMM TLLC residential environment was an excellent venue for the RESPECT project. For most students, this was the first longitudinal clinical interaction they had experienced. Students identified continuity of care, challenging psychosocial dynamics, and service-learning orientation as key factors in their overall satisfaction with the RESPECT experience. Students provided important feedback regarding potential improvements in the project, such as making greater use of web-based interaction and social networking to fill gaps in communication across disciplines.

There were only a few negative comments. Some students felt time pressures during the actual health screening visits, with one student remarking, "I couldn't do my part." Despite the fact that all students were routinely provided institutional email addresses and most, if not all, had mobile phones, students found communication among team members difficult outside of the scheduled project sessions. 
9

Service Learning for Interprofessional Education

Infante, ArevaloFlechas, Ford, Partida, Ketchum, Pollock, \& Infante

Journal of Research in Interprofessional Practice and Education

Vol. 5.1

May 2015

\section{Discussion}

Although health professions students rarely train together, they are expected to quickly learn how to interact appropriately with each other after graduation for the benefit of the patient and healthcare systems. Several major IPE initiatives on academic health centre campuses took place in the 1970s and 1980s, but activity waned thereafter for a variety of reasons [2]. Interest in IPE has recently reawakened due to the perception that more comprehensive and especially preventive healthcare can be delivered at lower cost through highly efficient teams. In addition to enabling positive health and economic benefits, there may also be a role for IPE in avoiding negative consequences. Recent evidence suggests, for example, that interprofessional conflict is associated with negative patient outcomes, such as those due to medical errors [10].

Conversely, IPE could be part of the solution for minimizing the negative effects of interprofessional conflict [11]. For example, newly trained health professionals often enter into employment agreements with each other, even though they never actually worked together during their education. Thus, IPE during health professions education may be an important factor in workplace satisfaction. It has been proposed that the ideal time to develop positive attitudes about other members of the healthcare team is during training, when students are less likely to have entrenched attitudes and exhibit maladaptive behaviours $[3,12]$.

Recently, IPE has begun to be linked with CSL in the manner described in this article. Thus far, published reports have focused on establishing and evaluating various models using individual participant reflections and focus groups $[13,14]$. To our knowledge, quantitative outcomes of CSL-based IPE projects with respect to student attitudes and perceptions have not been reported.

The RESPECT project placed students from four disciplines (dental hygiene, dentistry, nursing, medicine) together in a CSL environment under the supervision of faculty from each discipline. This corresponded to one of three Institute of Medicine definitions of interdisciplinary education: "students from more than one health profession taught by faculty from more than one profession" [5]. When discussing the results of the program, it is important to note that the RESPECT project students were already participating in CSL programs, either elective or mandatory, and volunteered to be part of the RESPECT project. Students may also have felt a degree of support from the presence of faculty members from their own educational programs who held similar positive views about the value of IPE.

Given the student selection process and voluntary nature of the program, it is not surprising that students were positively predisposed to the goals of the project. Nevertheless, substantial improvements were noted in the areas of student confidence with respect to being part of a multi-disciplinary team and understanding of the training requirements of different healthcare professionals (Tables 3 and 4). Students also had positive responses to the informal TLLC environment and the longitudinal nature of the clinical experience.

Faculty observations were helpful in analyzing the project and planning for future extensions. The experience of the upper-level students was helpful in keeping the project activities on task. Similarly, the fact that the students were recruited from existing 
10

Service Learning for Interprofessional Education

Infante, ArevaloFlechas, Ford, Partida, Ketchum, Pollock, \& Infante
Journal of Research in Interprofessional Practice and Education

Vol. 5.1

May 2015 activities in humanism and community service helped to ensure commitment to the goals and objectives of the RESPECT project. As with any volunteer activity and involving students with different schedules, it was difficult to find dates that were acceptable to all participants. This was especially problematic because the individual schools at our academic health centre had different academic calendars. Consideration will be given to consolidating future student participation into a shorter time period.

Because our academic health centre has recently chosen to emphasize IPE as a major institutional goal, faculty and students involved in RESPECT discussed, during the focus group, the ramifications of enlarging the program, making participation mandatory, and integrating an IPE project into the regular curriculum. While the inclusion of other disciplines, such as pharmacy, physical therapy, and others, into the teams was seen as beneficial, there were concerns about increased complexity in coordination and dilution of impact by becoming too diffuse. Finding enough additional venues with similar characteristics as the SAMM TLLC was also an issue. In this context, the use of simulations to deliver IPE has been explored [15]. On a positive note, scheduling issues could be reduced by integrating IPE activities into the regular curriculum and co-ordinating the academic calendars of the various schools. Reviewing previous attempts to formally integrate IPE programs into other academic health centres may be instructive and, indeed, cautionary [2]. Overall, the faculty and students who participated in this study were positive about continuing RESPECT.

\section{Acknowledgement}

The authors thank Linda Ximenes, Ximenes \& Associates, San Antonio, TX, for dedicated and professional facilitation services.

\section{Abbreviations}

IPE: Interprofessional education

CSL: Community service learning

\section{Note}

1. Dedicated to the memory of Taline "Talley" Dadian Infante-leader, teacher, colleague,friend, wife. She will always be a source of inspiration for the RESPECT team.

\section{References}

1. Larson, E. (1995). New rules for the game: Interdisciplinary education for healthprofessionals. Nursing Outlook, 43(4), 180-185.

2. Baldwin, D.C., Jr. (2007). Some historical notes on interdisciplinary and interprofessional education and practice in health care in the USA. Journal of Interprofessional Care, 21 (S1), 23-37.

3. Jacobsen, F., Fink, A.M., Marcussen, V., Larsen, K., \& Hansen, T.B. (2009). Interprofessional undergraduate clinical learning: Results from a three year project in a Danish Interprofessional Training Unit. Journal of Interprofessional Care, 23(1), 30-40.

4. Baldwin, D.C., Jr. (2007).Some historical notes on interdisciplinary and interprofessional education and practice in health care in the USA. Journal of Interprofessional Care, 21 (S1), 23-37.

5. The Definition and Principles of Interprofessional Education. Centre For The Advancement Of Interprofessional Education (CAIPE). http://caipe.org.uk.

6. Anonymous. (1988). Learning together to work together for health. Report of a WHO Study Group on Multiprofessional Education of Health Personnel: the Team Approach. World Health Organization Technical Report Series, 769, 1-72. 


\section{JRIPE}

Service Learning for Interprofessional Education

Infante, ArevaloFlechas, Ford, Partida, Ketchum, Pollock, \& Infante

\section{Journal of Research in Interprofessional Practice and Education}

7. Clark, P.G. (2006). What would a theory of interprofessional education look like? Some suggestions for developing a theoretical framework for teamwork training 1. Journal of Interprofessional Care, 20(6), 577-589.

8. National Service Learning Clearinghouse. http://www.servicelearning.org/

9. Thannhauser, J., Russell-Mayhew, S., \& Scott, C. (2010). Measures of interprofessional education and collaboration. Journal of Interprofessional Care, 24(4), 336-349.

10. Baldwin, D.C., Jr., \& Daugherty, S.R. (2008). Interprofessional conflict and medical errors: Results of a national multi-specialty survey of hospital residents in the US. Journal of Interprofessional Care, 22(6), 573-586.

11. Stewart, M., Purdy, J., Kennedy, N., \& Burns, A. (2010). An interprofessional approach to improving paediatric medication safety. BMC Medical Education, 10, 19.

12. Hind, M., Norman, I., Cooper, S., Gill, E., Hilton, R., Judd, P., \& Jones, S.C. (2003). Interprofessional perceptions of health care students. Journal of Interprofessional Care, 17(1), 21-34.

13. Bridges, D.R., Davidson, R.A., Odegard, P.S., Maki, I.V., \& Tomkowiak, J. (2011). Interprofessional collaboration: Three best practice models of interprofessional education. Medical Education Online, 16.

14. Pechak, C., Gonzalez, E., Summers, C., \& Capshaw, S. (2013). Interprofessional education: A pilot study of rehabilitation sciences students participating in interdisciplinary international servicelearning. Journal of Allied Health, 42(3), e61-66.

15. Reese, C.E., Jeffries, P.R., \& Engum, S.A. (2010). Learning together: Using simulations to develop nursing and medical student collaboration. Nursing Education Perspectives, 31(1), 33-37. 